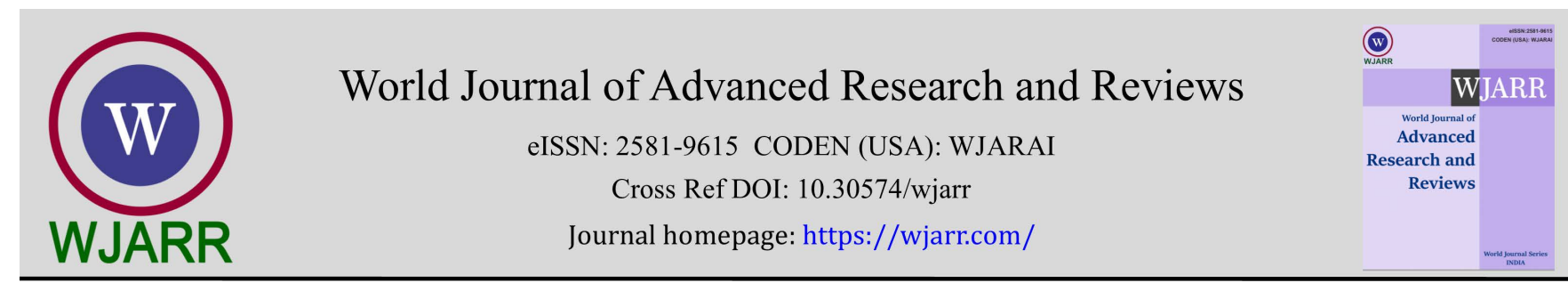

(REview ARTICLE)

Check for updates

\title{
Writing research proposal
}

\author{
S .Vasanthakumari * \\ Associate Professor, Department of Pediatric Nursing, School of Nursing and Midwifery, Institute of Health \\ Sciences, Wollega University, Ethiopia, East Africa.
}

World Journal of Advanced Research and Reviews, 2021, 10(01), 184-190

Publication history: Received on 01 March 2021; revised on 06 April 2021; accepted on 08 April 2021

Article DOI: https://doi.org/10.30574/wjarr.2021.10.1.0138

\begin{abstract}
A research proposal is a written document specifying what a researcher intends to study and written before beginning the research which communicate research problem and proposed methods of solving it. A research proposal should be built on a concrete plan to conduct academic or scientific research. Types of proposals include internal, external, solicited, unsolicited, preproposals, continuation or non-competing and renewal or competing. Purpose of a Research Proposal is to convince the organization and readers .Characteristics need to be based on attention, interest, desire and action. Qualities of good proposal include specific scope, realistic nature, appropriate credentials, fulfill needs, beneficial, short and simple. Need for good preparation of proposal is vital in formulating proposal, assisting researcher and improving the research quality. Functions of Proposal consists to synthesize critical thinking, clarifies own thinking, refine proposed research, communicate ideas, open thinking and negotiation between researcher and involved parties. Basic composition of Proposal needs a beginning, middle and an end. Typical proposal format includes title, abstract, introduction, background, preliminary studies, research methodology, budget, curriculum vitae for principal investigators, appendix and human subjects. Proposal development strategies and writing tips includes use of outline, listings, visuals, forecasting, internal summaries, significant issues , sequencing components , review , edit, proof read , avoiding overkill point and errors . Proposals are turned down when problems are trivial, complex, nebulous, diffuse without clear aim, lack of sufficient evidence, imagination and originality.
\end{abstract}

Keywords: Research proposal; Researcher; Research problem; Composition of proposal; Strategies; Tips

\section{Introduction}

A research proposal is a written document specifying what a researcher intends to study and written before beginning the research which communicate research problem and proposed methods of solving it. Research proposal has the content and organization which are broadly similar to that for a research report, but proposals are written in the future tense indicating what the researcher will do and obviously do not include results and conclusions. [1-4]. Proposals can serve a number of purposes, one of which is to establish a two way contract between researchers and those from whom support is sought. A research proposal should be built on a concrete plan to conduct academic or scientific research. It outlines not only what a researcher plan on researching, but it also explains all the procedures for qualitative and quantitative study intended on using. [11-12].

\section{Definition}

Research Proposal is a document communicating a research problem, its significance, proposed procedures for solving the problem, and, when funding is sought, how much the study will cost. [3]

\footnotetext{
${ }^{*}$ Corresponding author: Dr S Vasanthakumari

Department of Pediatric Nursing, School of Nursing and Midwifery Institute of Health Sciences,Wollega University,Ethiopia, East Africa..

Copyright (C) 2021 Author(s) retain the copyright of this article. This article is published under the terms of the Creative Commons Attribution Liscense 4.0.
} 


\section{Types of proposals}

\subsection{Internal proposals}

Internal proposals are typically reviewed by one or more departments within the Organization for cost, practicality, and potential benefits. The purpose of an internal proposal is to suggest a change or an improvement within an organization which is sent to a superior within the organization who has the authority to accept or reject the proposal. Two common types of internal proposals are routine and formal proposals.[13].

\subsection{External proposals}

It is the type of proposal which one written from one separate, independent organization or individual to another such entity. The typical example is the independent consultant proposing to do a project for another firm. [13].

\subsection{Solicited proposals}

It is a document that identifies a specific research problem of interest to the funding agency for which they are specifically seeking a solution. Proposals submitted in response to a specific call issued by a sponsor. This type of proposals are solicitations typically called Request for Proposals (RFP), or Request for Quotations (RFQ), usually have specific requirements for format and technical content, and may specify certain award terms and conditions. [13].

\subsection{Unsolicited proposals}

Proposals submitted to a sponsor that has not issued a specific solicitation but is believed by the investigator to have an interest in the subject. It is the proposal submitted by an investigator in response to a "general call" for proposals that is issued by a funding agency or company in a field or area of study. It is vitally important for Researcher who has identified a funding source to obtain all of the relevant information on the specific grant program and its requirements. [13].

\subsection{Preproposals}

Preproposals are usually in the form of a letter of intent or brief abstract. These are requested by a sponsor who wants to minimize an applicant's effort in preparing a full proposal. After the preproposal is reviewed, the sponsor notifies the investigator if a full proposal is warranted. [13].

\subsection{Continuation or non-competing proposals}

In this type of proposal, there will be a confirmation regarding the original proposal and funding requirements of a multi-year project which the sponsor has already provided funding for an initial period (normally one year). Continued support is usually dependent on satisfactory work progress and the availability of funds. [13].

\subsection{Renewal or competing proposals}

The type of proposals which request continued support for an existing project that is about to end.[13].

\section{Purpose of a research proposal}

- Purpose of research proposal is to convince the organization and readers by Investigator in terms of

* Significance of the problem and worthy of study.

* Novel technical approach and likely to yield results.

* The investigator and his/her research team is/are the right group of individuals who carry out and accomplish the work described in the research proposal.

- The proposal also helps to match Researcher's research interest with an appropriate supervisor.

- The proposal is a key part of Researcher application, on which potential supervisors or organization will decide if the research is something they can support [3, 5-7]. 


\section{Characteristics of proposal}

- Any proposals offer a plan to fill a need, and reader will evaluate plan according to:

* How well written presentation answers questions about?

* What a researcher plan to do?

* How will researcher do it?

* When will researcher do it?

* How much time will researcher take in completing it?

- What will it cost?

- It is very important to review own work when Researcher has finished the work.

- Researcher has to read the whole document as closely as possible, checking for typographical errors and possible changes to improve the readability of the work.

- It may also be useful to revisit formative comments received from previous work absolved in this area. This will allow identifying things that Researcher have done well in the past, and it will help in avoiding the previous mistakes done.

- Dissertation / Theses proposals are typically 20 to 40 pages in length.

- Since Research proposal is persuasive in nature it should be based on the AIDA plan.

* Attention is caught towards what is being Proposed

* Interest is created by pointing out how the work will be executed.

* Desire has to be generated to accept the Proposal by highlighting the benefits and advantages

* Action is induced by persuasive reasoning [2-3,5-7].

\section{Qualities of a good proposal}

- Use of many number of factors that play role in converting this selling tool into a contractual commitment

- Understand customers need as well as the products and services.

- Specify the scope clearly

- Be realistic in estimate of time, money, material and personnel required by the researcher

- Establish credentials for accomplishing the task for the researcher

- Highlight the benefits that would accrue to the customer.

- Keep the proposal short and simple

- Use plain language.

- Mention the risks and benefits that are likely to occur [3, 7-8].

\section{Need for good preparation}

- This is vital for grant application in a competitive environment. Funding is very competitive.

- It assists the researcher in project formulation, planning, performance and monitoring of the research.

- The quality of the proposal contributes to the evaluation outcome as a poorly prepared proposal may not be considered at all or cannot be considered fairly $[3,9]$.

\section{Functions of a proposal}

- Research proposals usually help researchers to clarify their own thinking.

- By communicating ideas to writing, ambiguities about how to proceed can be identified and dealt with at an early stage.

- Proposals are intended to synthesize researcher's critical thinking and even can serve to ensure that the research questions and proposed methods are sufficiently refined to warrant initiation of the study.

- Research proposals are reviewed by others who can offer suggestions for conceptual and methodologic improvements and thus represent a mechanism for improving the study's contribution to knowledge.

- Proposals represents the means for opening communication between researchers and parties interested in the conduct of research.

- Proposals often serve as the basis for negotiating with other parties as well.

- Proposals are often incorporated into submissions to human subjects committees or institutional review boards. [2, 14-15]. 


\section{Composition of a proposal}

The most basic composition of a proposal, as with any other written document, is simple; it needs a beginning (the Introduction), a middle (the Body of material to be presented) and an end (the Conclusion/Recommendation).[2,5].

The INTRODUCTION presents and summarizes the problem intended to solve and solution to that problem, including the benefits the reader/group will receive from the solution and the cost of that solution [8-10].

The BODY of the proposal should explain the complete details of the solution, how the job will be done which should be broken into separate tasks; what method will be used to do it, including the equipment, material, and personnel that would be required; when the work will begin, when the job will be completed. It should also present a detailed cost breakdown for the entire job [8-10].

The CONCLUSION should emphasize the benefits that the reader will realize from the solution to the problem and should urge the reader to action. It should be encouraging, confident and assertive in tone. Facts must lead logically and inevitably to the conclusion and/or the solution presented. Evidence should be given in a descending order of importance, beginning with the most important evidence and ending with the least important [8-10].

\section{Typical proposal format}

Title - The title of the proposal should be short, accurate, and clear. It should be a single sentence containing ten or fewer words. Acronyms and technical jargons need to be avoided as reviewers may not come from similar technical specialty [2-3].

Abstract - As in a technical paper, the proposal abstract should "abstract" the project for the reader. It should be a brief that is 100 - 200 words with tightly worded summary of the project, its objectives, significance of the problem, scope of the project, the methods used, identity and relevant technical expertise of the research team, and expected result. This section has to be written last so that its content indeed abstracts the proposal $[2-3,7]$.

Introduction - It describe to introduce the research problem, its significance, and the technical approach of Researcher's work will take to investigate/solve the problem. It should introduce the research team that will carry out the work [2$3,8-9]$.

Background - This section should present a concise review of the primary literature relevant to the proposed research efforts. It should include key literature sources cited, up to date references, and Critical appraisal of the literature [78].

The background section should be constructed to inform the reader concerning:

- Where the study fits in?

- It should clearly state why the project should be done?

- Does the work take a bold new direction, build on the prior work of others in the field mentioning the authors, address flaws in previous work mentioning authors again, develop infrastructure (instrumentation, methodology, collaborations) that will take an exciting new directions? [2-3,7-10].

\subsection{Preliminary Studies}

If the project builds on past studies from researcher's work, then should include a brief section outlining what researcher have already accomplished and explain how these results relate to the work outlined in the present proposal. If the ideas, Researcher proposing are novel, then it is especially important to include this section and to present evidence supporting the probable success of the project [4-5, 7-9].

\subsection{Research Methodology}

This section should outline Researcher's plan of attack. Specific information that should be contained in this section includes information on the research team and its technical expertise as it relates to the project, a realistic timeline, description of the specific experiments that will be accomplished together with alternate plans in case of potential difficulties/challenges. If more than one person will do the work described in the proposal then a division of labour should be provided together with an explanation of why each person is best qualified to do the work described. The 
timeline should define the length of the project and provide a schedule of who will do what specific tasks and approximately when during the project period. Also can include problems than can occur and how Researcher will be able to handle them in such a way that results in meaningful outcome [3-4,7-9].

\subsection{Budget}

The budget should identify the anticipated cost for everything (salaries, materials, instrumentation, travel costs, etc.) that will be required in order to accomplish the research project. Usually budgets are prepared and submitted as tables with prescribed format. A budget justification typically accompanies the budget request. The budget justification is simply an explanation, item-by-item, stating why Researcher must spend the money requested in order to carry out the experiments planned. A thoughtful budget demonstrates that the project is well conceived and likely to yield quality results. Researcher should be sure to think through the budget requests carefully and make sure that all requests are thoughtfully justified [4-5,9-10]

\subsubsection{There are two major components in a budget}

- Direct costs are the costs that Researcher incurs that are directly attributable to the project. Examples of direct costs include personnel salary, fringe benefits, materials and supplies, major instrumentation, and travel costs.

- Subcontractor costs are costs incurred if working on a collaborative project with an investigator at another institution, where researcher will need to include the costs that they will incur in carrying out the proposed work. The collaborator of Researcher is viewed as a subcontractor in terms of the grant proposal. Their institution may assess its own indirect costs and those will also need to be included in researcher's $r$ budget request to the funding agency.

- Indirect costs are the facilities and administrative costs that are incurred by the institution/employer in support of the research activities. Indirect costs are often assessed on either a modified total direct costs basis (MTDC) or a total direct costs basis (TDC). The MTDC and TDC rates are set by your institution so be sure to check with them to determine what the current rates are [9-10].

\subsection{Curriculum Vitae for Principal Investigators}

Most funding agencies require the principal investigator(s) to include some form of curriculum vitae. Curriculum vitae are the academic version (extended) of a resume. They provide useful information on the education, technical expertise, and research productivity of the principal investigator. In an effort to ensure the brevity and uniformity of the information provided, many funding agencies require that this information be provided according to a specific format only [7-10].

\subsection{Appendix}

This ancillary section should be used only to provide secondary information that is relevant to the research project. For example, Letter of collaboration, Permission letter and detailing the specific support provided for the project in terms of personnel, equipment, research materials, results, etc. Some funding programs do not allow investigators to submit appendices so need to find in advance whether or not researcher can submit supporting materials and to know if any limitations exist concerning these materials (content, page limits, etc.) [7-10].

\subsection{Human Subjects}

Includes obtaining ethical approval for the project through institution's office of Institutional Compliance when it involves experimentation on either animals or people [5-6].

\section{Proposal development strategies and writing tips}

- Use outline formats and listings whenever possible to break up narrative texts.

- Use visuals to enhance and explain abstract concepts and relationships. (Do not overuse.)

- It should not overkill a point and has to state it, support it, and move on to the next point.

- Use forecasting and internal summaries to help the reader know where they are and where they are going.

- Be generous with transitions as they will help the reader to know where they have been and where they are going

- Avoid equivocal language, such as: " might, ought to, could, may, should, hope, will consider, it appears".

- It should not avoid significant issues which apply to the project or potential problems which may be relevant to the project. 
- It is better to take a stand and discuss a process for dealing with anticipated problems than to avoid these questions.

- Avoid impossible promises.

- Avoid unsupported subjective arguments.

- It should not assume that the reader will be intimately familiar with the subject.

- It has to sequence the components of the proposal in a logical manner.

* Carefully review, edit, and proof read again and again

* Get others to help, as in another opinion in a medical manner.

* Avoid errors in grammar, spelling, math, and maintain a clean overall appearance.

* A proposal should be readable, should not be missing pages, and should be written in the same consistent style throughout [14-17].

\section{Reason why proposals are turned down}

- The problem is trivial or is unlikely to produce new or useful information.

- The proposed research is based on a hypothesis that rests on doubtful, unsound or insufficient evidence.

- The problem is more complex than the author realizes.

- The description of the research leaves the proposal nebulous, diffuse, and without a clear aim.

- The proposed methodology, including tests and procedures, are unsuited to the objective. It may be beyond the competence of the investigator.

- The overall design is not carefully thought out.

- Statistical aspects are not given sufficient consideration.

- Approach lacks imagination or originality.

- Controls are either inadequately conceived or described.

- Proposed material for research is unsuited or difficult to obtain.

- The number of observations proposed is unsuitable.

- Available equipment is unsuited to the research.

- The problem is local in significance, production, or control, or otherwise fails to fall clearly in the mainstream of the discipline.

- The problem is intellectually premature, only a pilot study.

- The problem as proposed is overly involved with too many elements required to be investigated simultaneously [15-17].

\section{Tips for proposal preparation [16-17]}

- Selection of important topic

- Review of a scuccessful proposal

- Input from key people

- Adherance of instructions

- Attending to evaluation criteria

- The research team

- Justification of decisions

- Proposal critique

\section{Conclusion}

Research proposal should set out the central issues or questions that Researcher intends to address. It should outline the general area of study within which research falls, referring to the current state of knowledge and any recent debates on the topic, as well as demonstrate the originality of the proposed research. The proposal also gives Researcher an opportunity to demonstrate the ability to communicate complex ideas clearly, concisely and critically. 


\section{Compliance with ethical standards}

\section{Acknowledgments}

I would like to acknowledge Wollega University Management, Institute of Health Sciences Chief Academic and Research Director Mr.Lemessa Assefa , School of Nursing \& Midwifery Dean Mr.Eba Abdisa, IHS Research and Post Graduate Vice Dean Mr.Getahun Fetensa , Pediatric Nursing Department HOD Mr.Bizuneh Wakuma and Mr.Werku Etafa for the support and motivation.

\section{Disclosure of conflict of interest}

Author declares that there are no conflicts of interest in any form.

\section{References}

[1] Burns, Grove SK. Understanding Nursing Research: Building Evidence Based Practice. 5th Edition. Philadelphia: Saunders Publications; 2012.

[2] Riyami Asyal. How to prepare a Research Proposal. Oman Med J. 2008 Apr; 23(2): 66-69.

[3] Polit DF, Beck CT. Nursing Research: Principles and Methods. 9th Edition. Philadelphia : Williams \& Wilkins;2012.

[4] Grove Susan, Gray Jennifer. Understanding Nursing Research: Building an Evidence-Based Practice. 7th Edition. Philadelphia: Saunders Publications; 2018. p.528.

[5] Muhammad Syed SK . Basic Guidelines for Research: Research Proposal.First Edition Chittagong : Book Zone Publications; July 2016.p. 468 -488.

[6] Parahoo K. Nursing Research: Principles, Process and Issues. 2nd Edition. NewYork: Palgrave Mac Millian Ltd; 2006.

[7] Sherina MS. How to write a research proposal?. The Family Physician. 2005; 13(3): 30-32.

[8] Olk HR. How to write a research proposal. DAAD Information Centre Acra. German Academic Exchange Service (C). November 2003 . Available at https://static.daad.de/media/daad de/pdfs nicht barrierefrei/derdaad/was-wir-tun/191612 howto research proposal.pdf

[9] World Health Organization. Regional Office for the Western Pacific.a guide for : Health research methodology . training in research methods. $2^{\text {nd }}$ ed. Manila : WHO Regional Office for the Western Pacific;2001.

[10] Wong Paul TP. How to write a research proposal. International Network on Personal Meaning - Promoting Health, Spirituality and Peace through meaning. Featured article. May $8 ; 2002$.

[11] https://libguides.usc.edu/writingguide/researchproposal

[12] https://grammar.yourdictionary.com/grammar-rules-and-tips/how-do-you-write-a-research-proposal-foracademic-writing.html

[13] https://guides.library.illinois.edu/c.php?g=504643\&p=3454880

[14] https://www.sagepub.com/sites/default/files/upm-binaries/14134 Chapter1.pdf

[15] https://www.scribbr.com/dissertation/research-proposal/

[16] https://www2.fundsforngos.org/featured/free-top-25-tips-on-how-to-write-proposals-effectively-for-fundingsuccess/

[17] http://www.hunter.cuny.edu/genderequity/repository/files/gep-workshop-materials/proposal tips.pdf 